\title{
Performance of laying hens fed on practical diets containing different levels of supplemental biotin during the rearing and laying stages
}

\author{
BY C. C. WHITEHEAD \\ Agricultural Research Council's Poultry Research Centre, King's Buildings, \\ West Mains Road, Edinburgh EH9 3 JS
}

(Received 22 November 1979 - Accepted 20 February 1980)

I. The effect of biotin supplementation of low-biotin practical diets during rearing and laying stages on performance was studied in White Leghorn-type laying hens.

2. Biotin supplementation during rearing did not have any apparent effect on the condition of the bird at point-of-lay or on subsequent laying performance.

3. Biotin supplementation during lay did not have any beneficial effect upon egg number, egg size or food intake or food conversion efficiency.

4. Internal egg quality, as reflected by albumen height, was slightly improved by biotin supplementation of layer's diet.

5. Input-output relationships were calculated for the incorporation of biotin in egg yolk.

6. Metabolic measurements suggested that biotin concentration in egg yolk was the best criterion of biotin status in the hen.

7. It is concluded that practical diets contain sufficient biotin to support optimum egg-laying performance in hens.

Adult fowls have a requirement for biotin for hatchability of eggs, but the requirement for egg laying has not been established. Studies by Cravens et al. (1942) and Brewer \& Edwards (I972) have shown that, when diets virtually devoid of biotin were fed to hens, hatchability decreased rapidly to zero but egg laying continued apparently unaffected. However, these experiments involved the feeding of deficient diets for periods of only IO-I I weeks to hens with rates of lay low by modern standards. More recently, Bradley et al. (1976) reported that biotin supplementation of a practical diet resulted in a small increase in the rate of lay of Leghorn-type breeders.

Studies with broilers over the past few years have shown that biotin can have an important effect on performance (Payne et al. 1974; Whitehead \& Blair, 1974; Whitehead et al. 1976) and it has been suggested recently that the requirement for optimum performance is higher than had been supposed (Whitehead \& Bannister, 1978a). Since it is possible to formulate practical layers' diets containing quite low levels of available biotin, it was decided to investigate the biotin requirements of layers over the whole laying year on a scale larger than hitherto, using a modern strain of high-performance layer. The experiment encompassed both the rearing and laying stages to determine whether biotin supplementation of practical low-biotin diets during either period could result in improvements in any aspect of performance.

\section{EXPERIMENTAL}

\section{Plan and diets}

Six treatments involving different levels of biotin supplementation were given in the rearing stage of the experiment. The supplemental levels were $0.06 \mathrm{mg} / \mathrm{kg}$ from I-day-old to 6 weeks and 0 thereafter or $0,0.06,0.12,0.20$ or $0.40 \mathrm{mg} / \mathrm{kg}$ from I-day-old to 19 weeks. At I9 weeks, birds from the rearing groups given $0.06 \mathrm{mg} / \mathrm{kg}$ to 6 weeks and $0.12 \mathrm{mg} / \mathrm{kg}$ to 19 weeks 


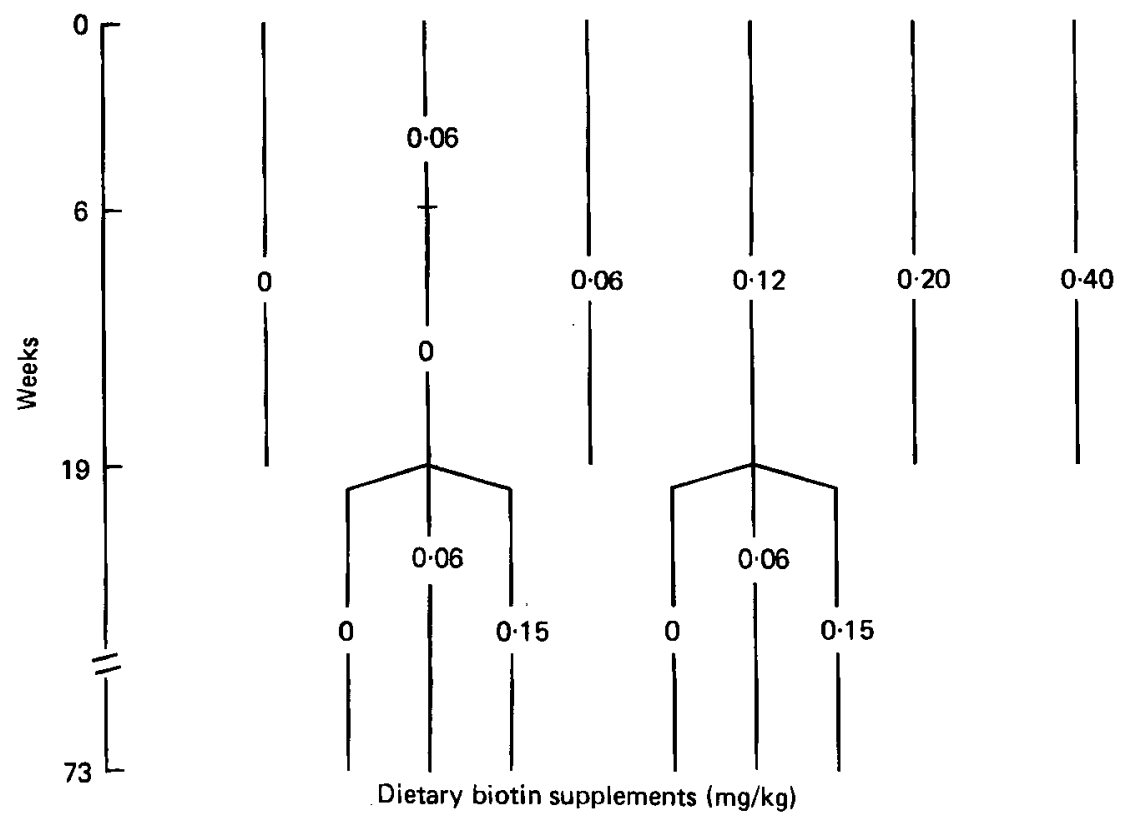

Fig. I. Supplemental dietary biotin levels fed to different groups of birds during different stages of the experiment.

were retained for the laying trial. During the laying stage, supplemental biotin levels of o, 0.06 and $0.15 \mathrm{mg} / \mathrm{kg}$ were each given to birds from each of these two rearing groups. The design of this part of the experiment was thus a 2 (rearing treatments) $\times 3$ (laying treatments) factorial. The over-all experimental design is represented diagrammatically in Fig. 1. Each rearing treatment was given to three pens of birds except the two treatments retained for the laying stage, which were each given to eighteen pens of birds. During the laying stage, the three supplemental levels were each given to 204 hens from each of the two rearing treatments. A total of 1224 hens was thus used for the laying stage.

The supplemental levels were chosen so that birds used in the laying stage would have been reared on either comparatively low or high dietary biotin levels. Nevertheless, the low group was given a small biotin supplement to guard against a possible occurrence of fatty liver and kidney syndrome (Payne et al. 1974; Whitehead \& Blair, 1974). The diets fed during the laying stage were calculated to provide very low, moderate and high levels of available biotin.

The compositions of the basal diets used during different stages of the experiment are shown in Table $\mathrm{I}$. The diets were formulated to contain levels of available biotin as low as could be achieved conveniently using the more commonly available practical food ingredients. For this reason they were based mainly on wheat, since the availability of biotin in this cereal has been estimated by Frigg (1976) to be less than $0 \cdot 10$. The total and available biotin contents of the basal diets, calculated on the basis of the results of Frigg (1976, 1977) are given in Table I. Assays of the total biotin contents of different batches of the diets gave values similar to the calculated values.

Other experimental diets were obtained by supplementing the basal diets with a commercial preparation containing $10 \mathrm{~g}$ D-biotin $/ \mathrm{kg}$ (Rovimix $\mathrm{H}$; Roche Products Ltd, Dunstable, Beds LU6 IBG). Analysis of these diets confirmed that the appropriate levels of additional biotin were present. 
Table I. Composition $(\mathrm{g} / \mathrm{kg}$ ) of basal diets fed during different stages of the experiment

\begin{tabular}{|c|c|c|c|}
\hline \multirow[b]{2}{*}{ Ingredient } & \multicolumn{2}{|c|}{ Rearing stage } & \multirow{2}{*}{$\underbrace{\text { Laying stage }}_{19-73 \text { weeks }}$} \\
\hline & o-6 weeks & 6-Ig weeks & \\
\hline Wheat & 767 & 707 & 755 \\
\hline Herring meal & 140 & 50 & 70 \\
\hline Soya-bean meal (445 g CP/kg) & 25 & 80 & 40 \\
\hline Meat-and-bone meal & - & - & 30 \\
\hline Field-bean meal & 30 & - & - \\
\hline Maize & - & 120 & - \\
\hline Isolated soya-bean protein* & - & - & 10 \\
\hline Limestone flour & 16 & 16 & 65 \\
\hline Dicalcium phosphate & I5 & 17 & 22 \\
\hline Lysine & - & $\mathrm{I} \cdot 5$ & 一 \\
\hline Salt & 2 & 3 & 3 \\
\hline Mineral supplement $\dagger$ & $2 \cdot 5$ & 2.5 & $2 \cdot 5$ \\
\hline Vitamin supplement & $2 \cdot 5$ & $2 \cdot 5$ & 2.5 \\
\hline Choline chloride ( $500 \mathrm{~g} / \mathrm{kg}$ ) & 0.4 & - & - \\
\hline \multicolumn{4}{|l|}{$\begin{array}{l}\text { Analyses } \\
\text { Measured }\end{array}$} \\
\hline $\mathrm{CP}$ & 204 & 170 & 165 \\
\hline Calcium & I3 & 13 & 36 \\
\hline Diethyl ether extract & 18 & 18 & 23 \\
\hline Total biotin $(\mathrm{mg} / \mathrm{kg})$ & 0.106 & 0.098 & $\begin{array}{c}0.087^{-} \\
\text {(range } 0.075-0.094)\end{array}$ \\
\hline \multicolumn{4}{|l|}{ Calculated } \\
\hline Total biotin $(\mathrm{mg} / \mathrm{kg})$ & 0.110 & 0.105 & 0.099 \\
\hline Available biotin (mg/kg) & 0.040 & 0.041 & 0.029 \\
\hline Metabolizable energy $(\mathrm{MJ} / \mathrm{kg})$ & I2.0I & $12 \cdot 05$ & $11 \cdot 38$ \\
\hline
\end{tabular}

\section{Birds and husbandry}

The birds used were $\mathrm{H} \& \mathrm{~N}$ Nick Chicks obtained at I-d-old from a commercial hatchery (H \& N Inc., Dunbar EH42 IDU). Up to I9 weeks of age they were housed in floor pens containing a deep litter of white-wood shavings, forty-five birds per pen. Food and water were freely available at all times. Food consumption per pen was measured weekly and all birds were weighed at 6 and 18 weeks of age.

At 19 weeks, birds from the appropriate rearing treatments were transferred according to a randomized plan to single-bird battery cage units equipped with individual feeding troughs and communal drinkers. Food and water were again freely available at all times. Food consumption per bird was measured monthly and egg production per bird was recorded daily. All eggs laid on 2 days each week were weighed individually. Recording continued until the end of the experiment at 73 weeks of age when the birds were again weighed.

At 4, 18, 45 and 73 weeks the birds were examined for signs of biotin deficiency and blood samples were taken for measurement of pyruvate carboxylase (pyruvate: $\mathrm{CO}_{2}$ ligase (ADP); EC 6.4. I . I) activity. At 60 weeks, pooled plasma and yolk samples were prepared and stored at $-10^{\circ}$ until analysed for biotin, and eggs were taken for measurement of albumen height converted to Haugh units (Haugh, 1937) to allow for differences in egg size. 
Table 2. Rearing performance up to I 8 weeks of age of 'Nick Chick' pullets fed on diets containing different levels of supplemental biotin

\begin{tabular}{|c|c|c|c|c|c|c|c|}
\hline \multirow{2}{*}{$\begin{array}{l}\text { Supplemental } \\
\text { biotin }(\mathrm{mg} / \mathrm{kg}\end{array}$} & \multirow{2}{*}{$\begin{array}{l}\text { No. of } \\
\text { replicates }\end{array}$} & \multicolumn{2}{|c|}{ Live wt (g) at: } & \multicolumn{2}{|c|}{ FCE } & \multicolumn{2}{|c|}{ Mortality (\%) } \\
\hline & & 6 weeks & 18 weeks & o-6 weeks & $7-18$ weeks & $0-6$ we & 8 weeks \\
\hline 0 & 3 & 453 & 1309 & 0.381 & 0.153 & 0 & 0 \\
\hline 0.06-6 weeks & 18 & 460 & 1272 & 0.376 & 0.145 & $\mathrm{I} \cdot 7$ & 0.7 \\
\hline $0.06-18$ weeks & 3 & 452 & 1288 & 0.360 & 0.152 & $2 \cdot 2$ & 0 \\
\hline $0.12-18$ weeks & 18 & 456 & 1272 & 0.398 & 0.147 & $1 \cdot 5$ & 0.1 \\
\hline $0.20-18$ weeks & 3 & 455 & 1285 & 0.326 & 0.149 & $3 \cdot 7$ & 0.2 \\
\hline $0.40-18$ weeks & 3 & $45^{8}$ & 1262 & 0.362 & 0.145 & $4 \cdot 4$ & 0 \\
\hline \multicolumn{8}{|l|}{ SED } \\
\hline Min rep & & II 99 & 19.8 & 0.027 & 0.0037 & & \\
\hline Max-min & & $9 \cdot I$ & $15 \cdot 1$ & 0.021 & 0.0028 & & \\
\hline Max rep & & 4.9 & $8 \cdot 1$ & 0.011 & 0.0015 & & \\
\hline
\end{tabular}

FCE, food conversion efficiency (live weight gained/unit of food consumed).

SED: Min rep, Max-min, Max rep standard errors of differences between groups with minimum replication, maximum and minimum replication and maximum replication.

* No. of pens, each containing forty-five birds, in each treatment.

\section{Methods}

Blood pyruvate carboxylase activities were measured using the methods described by Bannister \& Whitehead (1976) and Whitehead \& Bannister (1978b); enzyme activity was expressed as $\mathrm{nmol}{ }^{14} \mathrm{CO}_{2}$ incorporated/g haemoglobin per min at $38^{\circ}$.

Biotin was measured by a microbiological method using Lactobacillus plantarum (Wright \& Skeggs, 1944).

\section{RESULTS}

\section{Rearing performance}

The effects of the different dietary biotin levels on live weight, food conversion efficiency (FCE) and mortality at 6 and 18 weeks of age are given in Table 2. Live weight was very similar in all groups at 6 weeks. At 18 weeks it was highest in the group given the basal diets throughout but, because of the low extent of replication, the difference was not statistically significant. FCE showed no significant dietary effects or trends.

Mortality was low throughout the rearing stage, the bulk of the deaths occurring during the first few days of the experiment mainly as a result of septic yolk sacs. There were no instances of fatty liver and kidney syndrome and none of the birds given the unsupplemented basal diets died during the rearing stage.

\section{Laying performance}

The flock as a whole performed well. The first eggs were laid during the 2 ist week and the mean age at first egg was 22 weeks. The peak rate of production was $93 \%$ (hen-day basis) during week 28. Average production to 72 weeks per hen housed at 19 weeks was $27 I \cdot 3$ eggs.

The performance results for the laying stage are given in Table 3. They were analysed according to rearing and laying treatments by analysis of variance. Values missing as a result of mortality were replaced by calculated values.

There were no interactions between rearing and laying treatments in any aspects of performance measured; neither was there any significant effect of rearing treatment on subsequent performance.

There was no significant $(P>0 \cdot I)$ effect of laying treatment on any aspect of egg production performance. The birds on each treatment came into lay at the same time and laid 


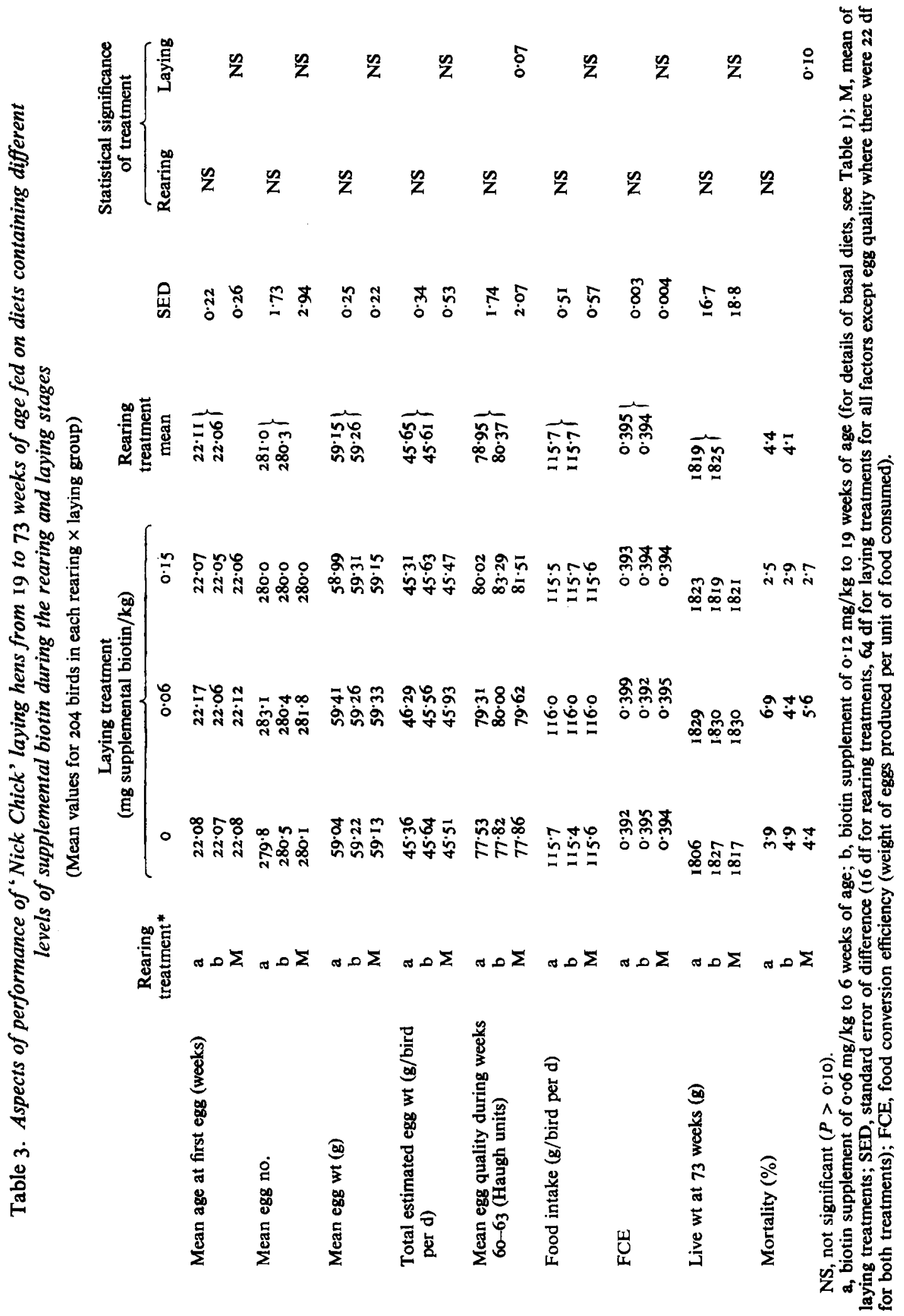


Table 4. Intake of dietary biotin and excretion of biotin in egg yolk of 'Nick Chick' laying hens fed on diets containing different levels of supplemental biotin

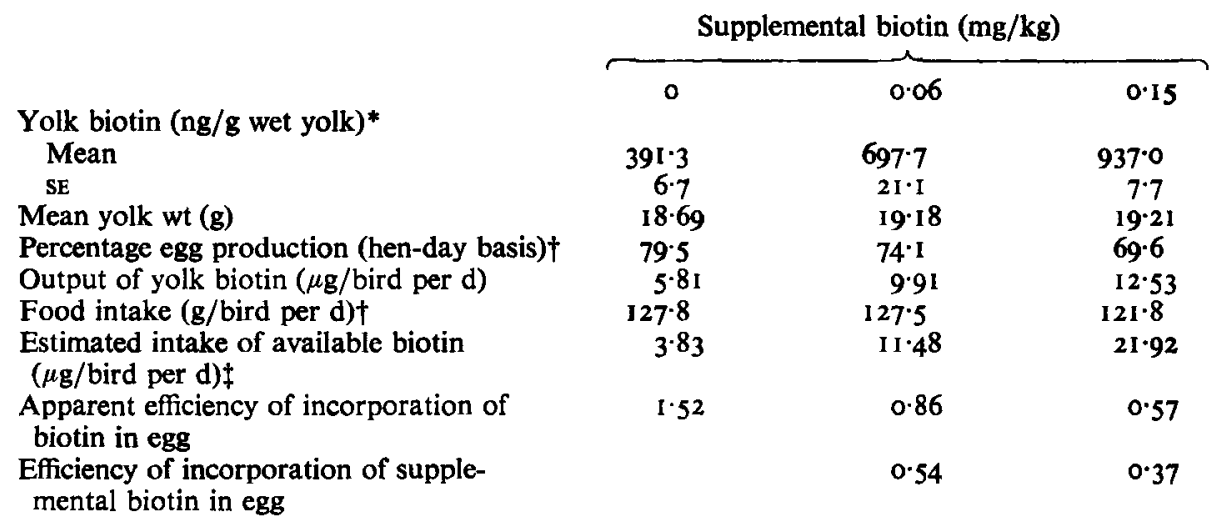

* Duplicate analyses on sample of yolk pooled from thirty eggs collected from groups of twelve birds in each treatment over a $4 \mathrm{~d}$ period during week 60 .

+ Performance results are means for the same groups of birds over a 4-week period incorporating the collection period.

¥ Calculated on the basis of the basal diet containing $0.03 \mathrm{mg}$ available biotin $/ \mathrm{kg}$ (see Table ).

similar numbers of eggs of very similar weight. Food intake and FCE were virtually identical in the three groups, with the result that there was little difference in live weight at the end of the experiment.

Meaningful treatment effects occurred possibly in internal egg quality, measured in Haugh units, over a 3-week period from week 60 . There was some day-to-day variation in quality and the values quoted in Table 3 contain corrections for collection day by analysis of covariance. The standard errors are thus approximate. There was no evidence of an effect of rearing diet; however, there was a suggestion that Haugh units increased in an approximately linear way with the biotin content of the laying diet, at a rate of 0.025 Haugh units $/ \mu \mathrm{g}$ biotin. This increase had a standard error of 0.0137 and was significantly different from zero $(P<0.07)$.

Mortality throughout the laying stage was very low over all and least with the highest level of biotin. Causes of death were varied, the most common being egg peritonitis and septicaemia, but there was no pattern with treatment. Effects of treatment on total mortality were estimated by fitting, by maximum likelihood, an additive model on the logit scale as described by Dyke \& Patterson (1952) and Nelder \& Wedderburn (1972). There was no effect of rearing diet but the observed effect of the laying diet was significant $(P<0 \cdot 10)$.

\section{Biotin transfer to the egg}

Measurements of biotin in pooled samples of egg yolk showed large differences between treatments (Table 4). Using performance values for the groups of birds from which the eggs were collected, the daily output of biotin in eggs was calculated for each treatment. On the basis of the available biotin content calculated for the basal diet (Table 2), the daily intake of available biotin was estimated for each treatment. For the basal diet, the daily output in yolk was approximately $50 \%$ greater than the estimated intake. The efficiencies of incorporation of the supplemental biotin into the eggs were 54 and $37 \%$ for the 60 and $150 \mu \mathrm{g} / \mathrm{kg}$ levels respectively. 
Table 5. Plasma biotin concentration and blood pyruvate carboxylase (pyruvate- $\mathrm{CO}_{2}$ ligase (ADP-forming), EC 6.4.I.I ; PC) activity at different stages in 'Nick Chick' pullets fed on diets containing different levels of supplemental biotin

(Mean values with their standard errors for duplicate assays on pooled samples from twelve birds/treatment. $\mathrm{PC}$ activity is expressed as $\mathrm{nmol}{ }^{14} \mathrm{CO}_{2}$ incorporated/g haemoglobin per min at $38^{\circ}$ )

\begin{tabular}{|c|c|c|c|c|c|c|c|c|c|c|}
\hline \multirow{3}{*}{$\begin{array}{l}\text { Age of bird (week } \\
\text { Supplemental } \\
\text { biotin }(\mathrm{mg} / \mathrm{kg})\end{array}$} & \multicolumn{8}{|c|}{ Blood PC } & \multirow{2}{*}{\multicolumn{2}{|c|}{$\overbrace{60}^{\begin{array}{c}\text { Plasma biotin } \\
(\mathrm{ng} / \mathrm{ml})\end{array}}$}} \\
\hline & \multicolumn{2}{|l|}{ ks) } & \multicolumn{2}{|c|}{18} & \multicolumn{2}{|c|}{45} & \multicolumn{2}{|c|}{72} & & \\
\hline & $\overparen{\text { Mean }}$ & SE & Mean & SE & Mean & SE & Mean & SE & Mean & $\mathbf{S E}$ \\
\hline 0 & $63 \cdot 3$ & $2 \cdot 0$ & $50 \cdot 0$ & $5 \cdot 0$ & Iי I9 & 2.6 & $6 \mathrm{I} \cdot 2$ & 3.6 & $26 \cdot 7$ & $2 \cdot I$ \\
\hline 0.06 & $86 \cdot 7$ & 2.5 & 49.4 & 2.5 & 65.2 & 3.4 & $76 \cdot 4$ & 3.9 & 53.0 & $8 \cdot 3$ \\
\hline 0.12 & 94.8 & 2.5 & $53 \cdot 3$ & $4 \cdot 6$ & & & & & & \\
\hline 0.15 & & & & & 55.0 & 1.8 & $74 \cdot 3$ & $4 \cdot 2$ & $5 I \cdot 9$ & $4^{\circ} 0$ \\
\hline 0.20 & $98 \cdot 0$ & $3 \cdot 3$ & $56 \cdot 7$ & $3 \cdot I$ & & & & & & \\
\hline 0.40 & $93 \cdot 5$ & 3.0 & $55 \cdot 4$ & $1 \cdot 7$ & & & & & & \\
\hline
\end{tabular}

Biotin status of birds

Plasma biotin levels and blood pyruvate carboxylase activities at different stages are given in Table 5. Plasma biotin level at 60 weeks was very much lower in hens fed on the basal diet, although a difference was not observed between birds fed on the two levels of supplemental biotin. Enzyme activity was depressed only at 4 weeks of age in birds fed on the low levels of biotin.

Regular inspection of the birds, especially their feet, failed to reveal any signs characteristic of biotin deficiency. The feet of birds on all the rearing treatments were in good condition at 18 weeks of age. However, by 73 weeks the feet of many birds showed areas of hyperkeratinization, particularly on the tips of the digits. Often there were haemorrhagic areas showing signs of bacterial infection. Although similar effects can be caused by biotin deficiency in chicks, the lesions were distributed evenly between the different treatments and were taken to be indicative of wire-floor abrasion rather than nutrient deficiency.

\section{DISCUSSION}

The performance of the flock in all aspects throughout different stages of the experiment was very good and comparable with that achieved by this strain under commercial conditions. In such circumstances, a nutrient insufficiency might be expected to be most easily detected. The basal diets were formulated to be low in available biotin; nevertheless, few beneficial effects of supplemental biotin were observed during either the rearing or laying stages.

During rearing, birds fed on the basal diet suffered least mortality, grew as well at all stages and were in as good condition at point-of-lay as those given supplemental biotin. On the assumption that the availability of biotin from wheat is only $0 \cdot 10$, the growth requirement, at least for pullets reared on deep litter, is thus apparently not higher than $0.04 \mathrm{mg}$ biotin $/ \mathrm{kg}$. The comparable requirement for broilers has been estimated to be $0.17 \mathrm{mg} / \mathrm{kg}$ (Whitehead \& Bannister, 1978a). However the curve established for the response of broiler growth to dietary biotin suggests that the much lower requirement of growing pullets is nevertheless appropriate for birds with such slow growth rates.

The low-biotin rearing group that continued into the laying stage was given a small biotin supplement up to 6 weeks of age. It was not thought that this supplement would 
have an effect on biotin status at point-of-lay, but might ensure a good start for the chicks. In the light of the results obtained, this supplement may not have been necessary to achieve a satisfactory point-of-lay pullet. However, during rearing the birds were fed on diets that contained generous amounts of other nutrients and experienced no apparent disease challenges. Under commercial conditions, it might be prudent nevertheless not to feed chicks on diets containing minimum biotin levels, for the first few weeks at least.

The group given the larger biotin supplement of $0.12 \mathrm{mg} / \mathrm{kg}$ throughout the rearing stage did not derive any subsequent benefit from it during the laying stage.

There were few effects of dietary biotin level during the laying stage that approached statistical significance. Egg production performance, in terms of number and size of eggs, was very similar in all groups, as were food intake and FCE. Mortality during the experiment was low and at the end of the experiment the birds had similar body-weights and did not show any lesions that could be attributed to diet. Egg quality, in Haugh units, was the one factor that did appear to show a relationship with biotin. It increased almost linearly with supplemental biotin and the effect was significant $(P<0.07)$. The actual egg quality of all groups was good but it is possible that, where poor egg-white quality occurs, a contributory factor may be dietary vitamin status.

The results of this experiment thus indicate that, in contrast to the broiler, the laying hen has a low requirement for biotin and even practical diets based on poor biotin sources do not require supplementation. These findings do not support those of Bradley et al. (I976) who reported a small response in egg production to supplemental biotin, despite the fact that the present experiment involved birds performing at a higher rate of egg production and fed on a basal diet containing less calculated available biotin.

The actual level of available biotin in the basal laying diet was not easily measurable but was calculated to be approximately $0.03 \mathrm{mg} / \mathrm{kg}$. The calculation depends considerably on the availability value used for wheat (availability in the other dietary ingredients is $\mathrm{I} \cdot 00$ ). The value taken for wheat was $0 \cdot 10$, which was thought to be reasonable in the light of the results of Frigg (1976) who, in well-conducted growth-response bioassays, obtained no detectable response to wheat samples from widely different sources. However, Anderson et al. (1978) have recently reported bioassays that suggest the availability in wheat may be approximately 0.40 , although their results do not seem so convincing as those of Frigg (1976).

The biotin input-output relationship was calculated on the basis of biotin measurements in pooled yolk samples (there is little biotin in albumen). With the basal diet, $50 \%$ more biotin appeared to be excreted in eggs than was calculated to be ingested. There are several possible explanations. Yolk biotin measurements were made on pooled samples; there was thus no indication of variability between eggs from the same hen or from individuals with widely different rates of lay. Alternatively, the diet may have contained more available biotin than calculated. An incorporation of biotin of $100 \%$ in the egg can be accounted for by assuming availability of biotin of 0.30 in wheat; however this method could not be regarded as satisfactory for estimating availability in food ingredients. Finally, there is the possible contribution of intestinally-synthesized biotin. It is not thought that much, if any, biotin of microbial origin can be absorbed by the chick (Coates et al. 1968) and in the hen the caeca, the site of maximum biotin synthesis, appears to be a net absorber of biotin (Sunde et al. 1950). Nevertheless, it is possible that biotin synthesized in other parts of the intestinal tract may contribute to the biotin supply of the adult hen.

Calculations on the transfer of supplemental biotin of the egg are less problematical. Efficiency was found to decrease with increasing biotin supply, being 0.54 and 0.37 with 0.06 and $0.15 \mathrm{mg}$ supplemental biotin $/ \mathrm{kg}$ respectively. This contrasts with the linear relationship between dietary and yolk biotin observed by Brewer \& Edwards (1972). 
Various metabolic factors were measured in an attempt to establish a suitable criterion of biotin status in hens. Blood pyruvate carboxylase activity gave some indication at 4 weeks of age but, as had been found in broilers and turkeys (Whitehead \& Bannister, $1978 \mathrm{~b}$ ) its relationship with biotin intake decreased with age so that by the time the birds were mature it gave no indication of biotin status.

Direct measurements of biotin were more useful. Plasma biotin levels showed a large difference between hens fed on the basal diet and those given supplemental biotin, although a difference between the two supplemental levels was not demonstrated. Plasma biotin concentrations were in the order of ten times greater than values reported for chicks (Frigg et al. 1973), but it has been confirmed that the plasma biotin concentration of pullets increases markedly when they start to lay eggs (M. Frigg, personal communication). This is consistent with observations by Hertze et al. (1949) that administration of oestrogen to sexually immature chicks raised serum biotin level 5-fold. Compared with plasma levels, yolk biotin from the same birds showed a better relationship with dietary biotin intake and this factor may be the best criterion of biotin status in laying birds.

I thank Mrs C. C. McCorquodale for statistical help with the planning of the experiment and analysis of results and F. Hoffman-La Roche \& Co., Basle, for biotin analyses.

\section{REFERENCES}

Anderson, P. A., Baker, D. H. \& Mistry, S. P. (1978). J. anim. Sci. 47, 654.

Bannister, D. W. \& Whitehead, C. C. (1976). Int. J. Biochem. 7, 619.

Bradley, J. W., Atkinson, R. L. \& Krueger, W. F. (1976). Poult. Sci. 55, 2490.

Brewer, L. E. \& Edwards, H. M. (1972). Poult. Sci. 51, 619.

Coates, M. E., Ford, J. E. \& Harrison, G. F. (I968). Br. J. Nutr. 22, 493.

Cravens, W. W., Sebesta, E. E., Halpin, J. G. \& Hart, E. B. (I942). Proc. Soc. exp. Biol. Med. 50, IoI.

Dyke, G. V. \& Patterson, H. D. (I952). Biometrics 8, I.

Frigg, M. (1976). Poult. Sci. 55, 2310.

Frigg, M. (1977). Verh. Schweiz. naturf. Ges. 157, 340.

Frigg, M., Weiser, H. \& Bollinger, A. (1973). Proc. V Wld. Vet. Poult. Ass. Congr., Munich, p. I 286.

Haugh, R. R. (1937). U.S. Egg Poult. Mag. 43, 552.

Hertze, R., Dhyse, F. G. \& Tullner, W. W. (1949). Endocrinology, 45, 45 I.

Nelder, J. A. \& Wedderburn, R. W. M. (1972). Jl R. statist. Soc. Ar35, 370.

Payne, C. G., Gilchrist, P., Pearson, J. A. \& Hemsley, L. A. (1974). Br. Poult. Sci. I5, 489.

Sunde, M. L., Cravens, W. W., Elvehjem, C. A. \& Halpin, J. G. (1950). Poult. Sci. 29, 10.

Whitehead, C. C. \& Bannister, D. W. (1978a). Proc. XVI Wld's Poult. Congr., Rio de Janeiro, p. 1927.

Whitehead, C. C. \& Bannister, D. W. (1978b). Br. J. Nutr. 39, 547.

Whitehead, C. C. \& Blair, R. (I 974). Wld's Poult. Sci. J. 30, 321.

Whitehead, C. C., Blair, R., Bannister, D. W., Evans, A. J. \& Jones, R. M. (1976). Res. vet. Sci. 20 , 180. Wright, L. D. \& Skeggs, H. R. (Ig44). Proc. Soc. exp. Biol. Med. 56, 95. 